\title{
Neutrophil Extracellular Traps and Endothelial Dysfunction in Atherosclerosis and Thrombosis
}

\author{
Haozhe Qi, Shuofei Yang ${ }^{\star+}$ and Lan Zhang ${ }^{\star+}$ \\ Department of Vascular Surgery, Renji Hospital, School of Medicine, Shanghai Jiao Tong University, Shanghai, China
}

OPEN ACCESS

Edited by:

Jixin Zhong,

Case Western Reserve

University, United States

Reviewed by:

Hugo Caire Castro-Faria-Neto, Oswaldo Cruz Foundation, Brazil

Neha Dixit,

DiscoveRx, United States

Shanzhong Gong,

University of Texas at Austin,

United States

*Correspondence:

Shuofei Yang

yangshuofei@gmail.com;

Lan Zhang

zhanglanrjxg@gmail.com

tThese authors have contributed equally to this work.

Specialty section:

This article was submitted to Inflammation,

a section of the journal

Frontiers in Immunology

Received: 08 May 2017

Accepted: 20 July 2017

Published: 07 August 2017

Citation:

Qi H, Yang S and Zhang L (2017) Neutrophil Extracellular Traps and Endothelial Dysfunction in Atherosclerosis and Thrombosis.

Front. Immunol. 8:928. doi: 10.3389/fimmu.2017.00928
Cardiovascular diseases are a leading cause of mortality and morbidity worldwide. Neutrophils are a component of the innate immune system which protect against pathogen invasion; however, the contribution of neutrophils to cardiovascular disease has been underestimated, despite infiltration of leukocyte subsets being a known driving force of atherosclerosis and thrombosis. In addition to their function as phagocytes, neutrophils can release their extracellular chromatin, nuclear protein, and serine proteases to form net-like fiber structures, termed neutrophil extracellular traps (NETs). NETs can entrap pathogens, induce endothelial activation, and trigger coagulation, and have been detected in atherosclerotic and thrombotic lesions in both humans and mice. Moreover, NETs can induce endothelial dysfunction and trigger proinflammatory immune responses. Overall, current data indicate that NETs are not only present in plaques and thrombi but also have causative roles in triggering formation of atherosclerotic plaques and venous thrombi. This review is focused on published findings regarding NET-associated endothelial dysfunction during atherosclerosis, atherothrombosis, and venous thrombosis pathogenesis. The NET structure is a novel discovery that will find its appropriate place in our new understanding of cardiovascular disease. In addition, NETs have high potential to be further explored toward much better treatment of atherosclerosis and venous thromboembolism in clinic.

Keywords: neutrophil extracellular traps, endothelial dysfunction, atherosclerosis, atherothrombosis, venous thromboembolism

\section{HIGHLIGHTS}

1. The NET structure, which has been clearly observed in the atherosclerotic plaque and venous thrombi, is a novel discovery that will find its appropriate place in our new understanding of cardiovascular disease.

2. This review summarizes the crosstalk mechanism between NETs and endothelial cells during the thrombosis and atherosclerosis.

Abbreviations: NETs, neutrophil extracellular traps; PMN, polymorphonuclear neutrophil; DNase, deoxyribonuclease; ECs, endothelial cells; VTE, venous thromboembolism; TLR, toll-like receptor; ROS, reactive oxygen species; NE, neutrophil elastase; PAD4, peptidyl arginine deiminase 4; G-CSF, granulocyte colony-stimulating factor; MPO, myeloperoxidase; IL, interleukin; CXCL, C-X-C motif ligand; LDL, low-density lipoprotein; DVT, deep venous thrombosis; PE, pulmonary embolism; vWF, von Willebrand factor; EDTA, ethylenediamine-tetraacetic acid. 
3. NETs have high potential to be further explored to progress toward much better treatment of atherosclerosis and venous thromboembolism in clinic.

\section{INTRODUCTION}

Polymorphonuclear neutrophils (PMNs) have a significant innate immune system function in protection against pathogen invasion. In addition to classical phagocytosis, PMNs can release chromatin, nuclear proteins, and serine proteases extracellularly to form [neutrophil extracellular traps (NETs)], which comprise net-like DNA fibers containing histones and antimicrobial proteins (1). NETs can entrap pathogens to limit their dispersion, trigger coagulation, and induce endothelial injury. Since the first characterization of NETs in 2004, studies of their effects have expanded to reveal unexpected roles in sterile inflammation induced by PMNs $(2,3)$. Notably, the antibacterial activity of NETs is abrogated by deoxyribonuclease (DNase), which can directly degrade the chromatin fibers that comprise the backbone of NETs (2). Vascular endothelial cells (ECs) maintain the balance between anticoagulation and immune response functions. Atherosclerosis and venous thromboembolism (VTE) are two major cardiovascular diseases associated with endothelial dysfunction. Atherosclerosis and thrombosis share many common risk factors, such as obesity, diabetes, smoking, hypertension, and hyperlipidemia; however, it remains unclear whether there are specific factors involved in the pathogenesis of both atherosclerosis and VTE (4).

Neutrophil extracellular traps can be detected in both atherosclerosis and thrombosis, and the existence of these structures could be perceived as a double-edged sword in the context of disease processes, as it may both attenuate tissue injury and amplify local inflammation, leading to deterioration in disease symptoms (5). Nevertheless, no specific explanations are available for the effects of NETs on vascular endothelial function and the promotion of atherosclerosis and thrombosis. In this review, we reveal potential mechanisms underlying NET formation and endothelial dysfunction in cardiovascular disease and examine current knowledge of the potential clinical implications of these structures.

\section{MECHANISM OF NET FORMATION}

Neutrophil extracellular traps are formed during inflammation and observed in vivo during infections (6). The existence of NETs indicates that PMNs may undergo an alternative form of programmed cell death, termed NETosis, allowing function of these structures in innate immune defense. Depending on the different triggers involved, signaling molecule receptors and membrane integrity, NETosis is described as either "vital" or "suicidal" (7-11). In "vital” NETosis, PMNs rapidly release nuclear DNA encircled by vesicles to the extracellular space without membrane perforation, in response to stimulation by platelets via toll-like receptor (TLR)-4, or Gram-positive bacteria via TLR-2, in a reactive oxygen species (ROS)-independent manner (12). "Suicidal" NETosis is characterized by strong activation of nicotinamide adenine dinucleotide phosphate oxidase by phorbol 12-myristate 13-acetate, interleukin-8 (IL-8), or various microbial pathogens, in a ROS-dependent manner $(13,14)$. NETs can be released via neutrophil lysis or through vesicular transport of nuclear or mitochondrial DNA, without membrane rupture $(12,15)$. Regardless of which type of NET occurs, the molecular contents of their structures are similar, and include histones, neutrophil elastase (NE), myeloperoxidase (MPO), proteinase 3, cathepsin, and gelatinase $(16,17)$.

Although neutrophils are transcriptionally active cells, the majority of their DNA is transcriptionally inactive and condensed into heterochromatin. Its decondensation is mediated by peptidyl arginine deiminase 4 (PAD4), which catalyzes the conversion of histone arginines to citrullines, reducing the strong positive charge of histones, and consequently weakening histone-DNA binding (18). Spikes in intracellular $\mathrm{Ca}^{2+}$ can activate PAD4 to propagate NET release, and PAD4-deficient mice are unable to form NETs in response to physiological activators, such as bacteria $(19,20)$. NE is considered essential for histone cleavage during NETosis; accordingly, secretory leukocyte peptidase inhibitor, an endogenous elastase inhibitor, can inhibit NETosis $(14,21)$. The central role of elastase in NETosis is corroborated by the inability of PMNs from elastase-deficient mice to undergo this process (22).

\section{NETS AND ATHEROSCLEROSIS}

Atherosclerosis is a cardiovascular disease accompanied by chronic vascular wall inflammation, endothelial dysfunction, and smooth muscle cell proliferation (23). Given the limited lifespan of PMNs and inadequate methods for their detection, the contribution of neutrophils to atherosclerosis has been underestimated (24). Additionally, the phenotype of PMNs can alter in response to inflammation, which has also resulted in the historical neglect of the role of neutrophils in the process of atherosclerosis (Figure 1A) (25). Hyperlipidemia can injure ECs, promoting lipid deposition and plaque formation, and usually represents the onset of atherosclerosis. Interestingly, hyperlipidemia induces neutrophilia, which is positively associated with atherosclerotic plaque burden (24). In addition, hypercholesterolemia can induce the synthesis of granulocyte colony-stimulating factor (G-CSF), a key cytokine in the regulation of granulopoiesis, through inducing increased levels of tumor necrosis factor- $\alpha$ and interleukin-17 (IL-17) (26). G-CSF stimulates the proliferation of myeloid precursors and reduces bone marrow $\mathrm{C}-\mathrm{X}-\mathrm{C}$ motif ligand (CXCL)-12 levels, thereby reducing the clearance of aged PMNs (27). In addition, hypercholesterolemia can enhance serum levels of CXCL1, which promotes PMN mobilization (28). Together, these data suggest that PMNs may play a role in stimulation of atherosclerosis.

Recent studies have indicated that PMNs attach themselves to atherosclerotic plaques, primarily through NET formation (Figure 1A). Components of NETs, such as cathepsin G and cathelicidins, exhibit monocyte-attracting activity in atherosclerotic plaques $(29,30)$. The cathelicidin-related antimicrobial peptide (CRAMP) residing in neutrophil secondary granules have potent effects on recruitment and activation of immune cells, such as monocytes and dendritic cells (31). NET-derived 


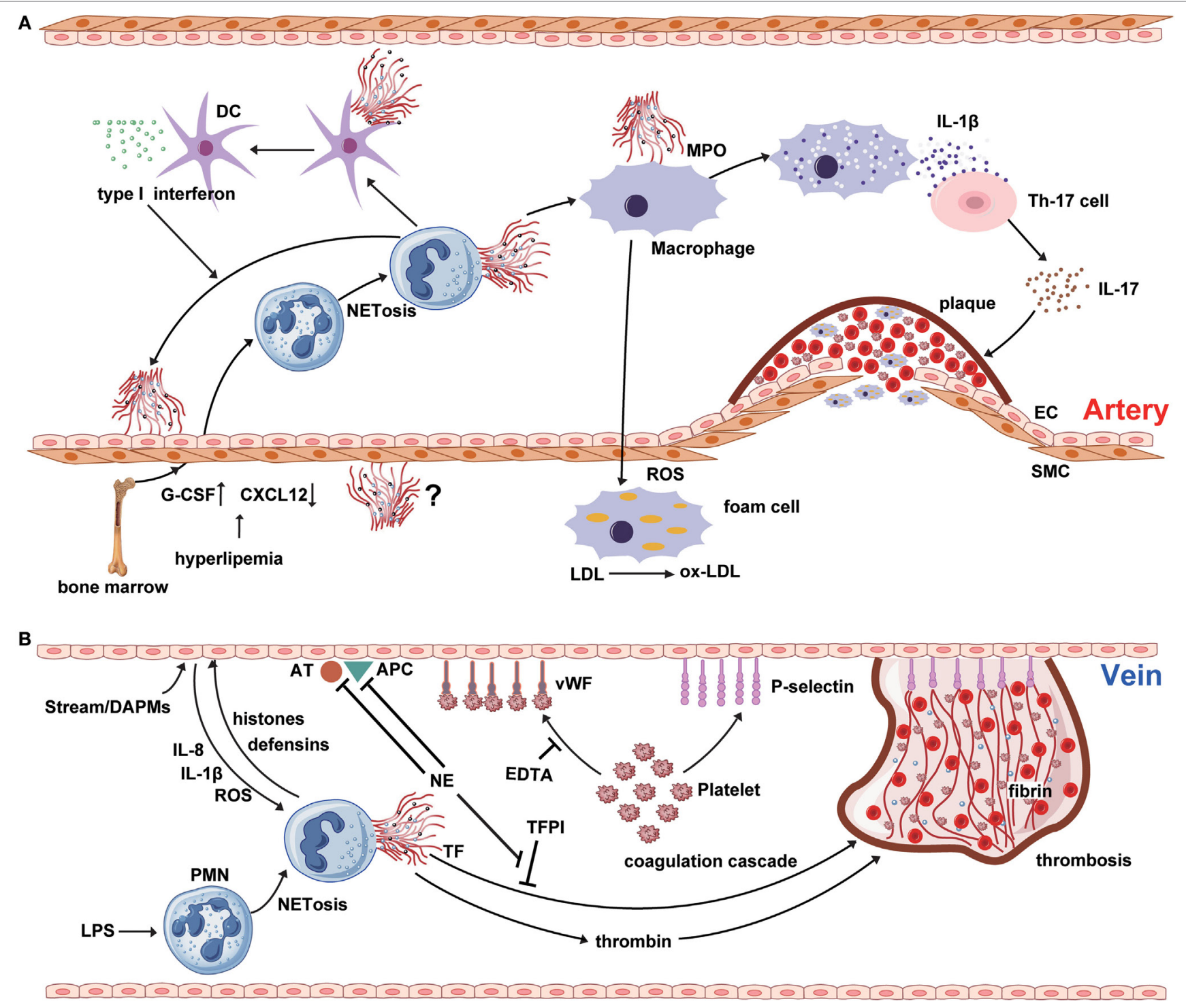

FIGURE 1 | NETosis interweaves atherosclerosis and thrombosis. (A) Neutrophil extracellular traps (NETs) are involved in the whole process of atherosclerosis. The myeloperoxidase from NTEs can stimulate macrophage to oxidize low-density lipoprotein (LDL) to ox-LDL and form the foam cell. The hyperlipidemia recruits neutrophil into circulation from bone marrow by upregulating the expression of granulocyte colony-stimulating factor and downregulating the level of C-X-C motif ligand -12, which is an important signal for the clearance and recruitment of aged neutrophils to the bone marrow. Cholesterol crystals can trigger the polymorphonuclear neutrophil (PMN) to release the NETs that prime the macrophages for pro-inflammatory cytokine production including IL-1 $\beta$. Then IL-1 $\beta$ activates Th17 cell to release interleukin-17, amplifying the immune cell recruitment into the atherosclerotic plaque. As another critical source of foam cell, SMC also takes part in atherosclerosis. However, there are few reports about the interaction between NETs and SMC. (B) NETs are released from PMNs, which are activated by LPS or other cytokines from injured endothelial cells. NETs promote the expression of von Willebrand factor and P-selectin on the surface of venous endothelium to entrap both platelets and red blood cells, thereby creating a scaffold for fibrin deposition. Meanwhile, histones and TF from the NETs structure induce the thrombin generation and activation via platelet-dependent or -independent mechanism. Tissue factor pathway inhibitor (TFPI) can abrogate the function of TF. However, utrophil elastase from NETs could degrade TFPI, antithrombin, and activated protein C.

CRAMP-deleted ApoE-deficient mice develop smaller plaques than ApoE-deficient mice, suggesting that CRAMP may be involved in plaque formation (32). Moreover, NETs have been identified as a major source of CRAMP, which is deposited directly on the inflamed endothelial surface in atherosclerotic vessels. Indeed, NET-derived CRAMP anchors to ECs, where it can link with formyl-peptide receptor 2 on classical monocytes, resulting in monocyte recruitment to ECs (33). After binding to the mannose receptor of macrophages, MPO from NETs induces the release of ROS, along with other pro-inflammatory macrophage-derived cytokines (23). Furthermore, proteinases from NETs affect plaque instability, while ROS from macrophages contributes to the modification of low-density lipoprotein (LDL) to produce ox-LDL, which promotes the development of foam cells $(34,35)$. NETs can also regulate cytokine production from macrophages in atherosclerosis (36). More precisely, cholesterol 
crystals function as danger signals, inducing interleukin-1 $\beta$ (IL-1 $\beta$ ) production and triggering NET release from PMNs. Subsequently, NETs stimulate cytokine release from macrophages and activate $\mathrm{T}$ helper 17 cells, resulting in amplified immune cell recruitment to the atherosclerotic plaque (36).

Research has underscored the importance of NETs in the regulation of lesion size in atherosclerosis, and suggests that these structures can induce endothelial dysfunction directly by activation and damage of ECs (37). Inhibition of PAD4 using chloramidine led to decreased atherosclerotic lesion size and carotid artery thrombosis delay in a mouse model, while these effects were not observed after treatment with neutrophil-depleting antibody, or of mice lacking a functional type I interferon receptor (37). These data indicate a critical direct role for NETs in atherosclerotic lesion formation via type I interferon. Mixture of cell free-DNA and granule proteins can stimulate plasmacytoid dendritic cells, leading to a strong type I interferon response and a deteriorating atherosclerotic plaque burden; however, the importance of the NET-derived type I interferon response in atherogenesis has been questioned, because NETs can also regulate cytokine production by macrophages in atherosclerosis $(36,38,39)$.

\section{NETS AND ATHEROTHROMBOSIS}

Atherothrombosis is the formation of a thrombus within an artery with atherosclerosis. Neutrophils as well as macrophages participate importantly in this disease process. In most cases, atherothrombosis follows rupture of atheroma, which may be triggered by NETs (8). Circulating leukocytes have a crucial role in atherothrombosis and systemic neutrophil counts are robust predictors of acute coronary events $(40,41)$. Moreover, complement activation can trigger PMN recruitment to the site of atherothrombosis in acute myocardial infarction (42). Coronary atherothrombosis specimens from patients with acute myocardial infarction contain numerous activated neutrophils (43-45). Sudden rupture of atherosclerotic plaques triggers platelet aggregation and fibrin deposition at the initial site of atherothrombosis to entrap circulating red blood cells. The interaction of thrombinactivated platelets with PMNs at the site of plaque rupture during acute ST-segment elevation acute myocardial infarction results in local formation of NETs (46). Elevated levels of circulating DNA and chromatin released from activated PMNs are independently associated with severe coronary atherosclerosis and the prothrombotic state (47). Interestingly, NETs are frequently found in lytic and fresh thrombus specimens, but never observed in organized thrombus (48). Hence, it can be assumed that NETs are involved at an early stage during the formation of coronary thrombus and lytic changes. A recent study involving evaluation of coronary atherothrombosis specimens demonstrated that NET burden and DNase activity in ST-elevation acute coronary syndrome are predictors of ST-segment resolution and infarct size (49).

Histological analysis of 26 thrombectomy samples from patients with acute myocardial infarction revealed that activated platelets present high-mobility group box 1 protein to PMNs, thereby inducing NET formation (50). The authors speculate that these NETs may contribute to plaque rupture and subsequent thrombus formation. In accordance with these findings, platelet-derived high-mobility group box 1 protein can facilitate NET formation and coagulation (51). Similarly, Riegger et al. analyzed 253 samples from patients with stent thrombosis after percutaneous coronary intervention (52). Approximately 23\% of the thrombi specimens contained NETs; however, no differences in the number of NETs were observed according to the timing of stent thrombosis, stent type, or in comparison with samples from patients with spontaneous myocardial infarction (52). Hence, recruitment of PMNs appears to be a hallmark of stent thrombosis.

As the main initiator of coagulation, with a critical role in arterial thrombosis, tissue factor (TF) has been investigated in patients with acute ST-segment-elevation myocardial infarction (53). Local accumulation of TF-bearing NETs is observed at sites of coronary thrombosis, and PMNs release NETs, thereby exposing TF in infarct-associated, but not non-infarcted, areas (53). In addition, neutrophil islets and NETs decorated with TF were detected in thrombi obtained from infarcted regions (46). Interactions between activated platelets and PMNs at sites of plaque rupture during acute myocardial infarction result in NET formation and delivery of active TF, which together foster thrombus formation. Notably, NETs were also identified as coated with IL-17, which promotes thrombosis by enhancing platelet aggregation in coronary thrombectomy samples (48). The role of NETs has also been examined in a model of myocardial ischemia-reperfusion, and a significant cardioprotective effect of NET-inhibition treatment on myocardial ischemia-reperfusion injury was clearly demonstrated (54).

\section{NETs AND VTE}

Deep venous thrombosis (DVT) and pulmonary embolism are designated 'VTE' in the clinic. Venous thrombogenesis is usually accompanied by inflammatory reactions of ECs (55). As a key element of the inflammatory response, NETs also play an important role in venous thrombogenesis (Figure 1B). Unlike atherothrombosis, the onset of venous thrombosis is primarily initiated by endothelial injury, caused by disturbance of the blood stream or endothelial dysfunction, and mediated via damage-associated molecular patterns (56). Subsequently, Weibel-Palade bodies derived from ECs secrete massive amounts of von Willebrand factor (vWF) and P-selectin, which adhere to platelets and recruit leukocytes $(57,58)$. NETs predominantly form during the organizing stage of human VTE development (59). At the local lesion site, platelets interact directly with PMNs and promote the production of NETs (60). Additionally, cytokines from activated ECs (e.g., IL-1 $\beta$, IL-8, and ROS) can accelerate NET formation (61). NETs, in turn, induce EC activation through NET-derived proteases; for example, histones and defensins (62). Additionally, purified histones can enhance thrombin generation through both platelet-dependent and platelet-independent mechanisms; however, platelet aggregation in response to histone $\mathrm{H} 3$ is inhibited by ethylenediaminetetraacetic acid (EDTA), suggesting that platelet aggregation is caused by the positive charge of histones (63-65). Intravenous administration of exogenous 
histones accelerates clot formation, whereas DNase treatment significantly delays the onset of DVT (66). In addition to clinical investigations, studies in mice have identified an association between the risk of DVT and high PMN counts, supporting an important and early role for NETs in venous thrombosis $(67,68)$.

In the process of thrombosis propagation, circulating nucleosomes act as a platform for the degradation of tissue factor pathway inhibitor, which is mediated by NE (69). The levels of circulating nucleosomes in DVT patients are significantly elevated, and may be a useful plasma marker for NET formation (70). In addition to providing an adhesive platform for platelets, NETs also support the adhesion of red blood cells (65). NETs maintain the stability of thrombus via vWF, fibronectin, and fibrinogen; vWF and fibrinogen can interact with histones, and fibronectin has a DNA-binding domain (71). Heparin can remove histones, leading to the destabilization of NETs (72). In vitro data support the ability of NETs to stimulate the activation of coagulation cascades and platelet adhesion, and fibrin deposition colocalizes with NETs in blood clots (69). Purified histones impair thrombomodulindependent protein $\mathrm{C}$ activation to enhance plasma thrombin generation (73). Furthermore, DNA and histones interact with and trap platelets, most likely via electrostatic interactions or TLRs (73). Together, the findings described above indicate that NETs make a substantial contribution to maintenance of the stability of venous thrombi.

Monocytes are recruited during thrombosis and thrombolysis; however, the specific function of monocytes in dissolving NET-induced thrombus requires further investigation. NETs colocalize with fibrins and vWF in venous thrombi, and vWF and fibrins constitute the main scaffold that must be fragmented in order to destroy the integrity of the thrombus structure (Figure 1B) $(65,66)$. In vitro, NETs can provide a scaffold for clots to induce resistance to tPA-induced thrombolysis (65). DNase is a strong nuclease present in blood and has the power to degrade protein-free DNA; however, the ability of DNase to degrade NET-derived chromatin is limited, because their chromatin is decorated with numerous proteases and histones. Interestingly, DNase can cooperate with the plasminogen system during chromatin degradation (74). In addition, NETs may recruit plasminogen from the plasma. Histone $\mathrm{H} 2 \mathrm{~B}$ can serve as a receptor for plasminogen on the surface of human monocytes/ macrophages and could potentially also serve this function in NETs (75). In vitro studies have shown that NET-derived NE and cathepsin $\mathrm{G}$ can degrade fibrin and enhance fibrinolysis in DVT (76). Plasma DNA concentrations correlate with D-dimer levels; therefore, it is plausible that circulating DNA may reflect the degradation of NETs within a thrombus $(70,77)$.

In immunothrombosis, NETs may function in capture of invasive pathogens, prevention of distant tissue involvement, concentration of pathogens for bactericidal killing, and recruitment of other immune cells to immune target sites (78). In models of sepsis, lipopolysaccharide can activate platelets and PMNs via TLR-4 to induce NETosis $(50,79)$. We have reported that PMNs from septic patients have significantly enhanced NET release, compared with those from healthy controls with increased risk of VTE (80). NET-associated immunothrombosis leads to more sturdy thrombi with reduced permeability and decreased susceptibility to thrombolysis, although this can be overcome with DNase treatment (81). In addition to sepsis, NETs and immunothrombosis have been implicated in other autoimmune diseases, including inflammatory bowel disease and vasculitis $(82,83)$.

\section{FUTURE CHALLENGES AND CLINICAL IMPLICATIONS}

Undoubtedly, more in-depth studies are needed to meticulously dissect the exact mechanisms of in vivo NET formation, and to clarify the importance of histone citrullination for NETosis (84). ROS generation by different types of leukocyte is a common trigger of NETosis; however, the exact mechanism of ROSinduced NETs formation and subsequent endothelial dysfunction is unclear (Figure 1). Moreover, how NET-derived proteases respond in atherosclerosis and thrombosis remains an open question. Movement from investigations of integrated NETs to study of more specific in vitro protease systems, which may better explain the phenomena associated with disease, is an interesting future prospect. NETs have been identified at each stage of cardiovascular disease. Nevertheless, whether NETs play different roles at different stages remains unknown. Additionally, it will be a challenge to explore whether NETs are involved in cross talk with smooth muscle cells, which are another major source of foam cells during atherosclerosis. Regarding DVT, it will be important to identify endogenous triggers of NET formation. Furthermore, whether the NETs involved in DVT are generated by cell lysis or a secretory process is another a critical question. A better understanding of NETosis, both with regards to structural constituents and context-specific functional decoration, will be a prerequisite to further elucidation of the role of NETs in atherosclerotic plaques and venous thrombus, and will be of paramount importance to the identification, validation, and implementation of the best molecular candidates for therapeutic targeting.

The notion that NETs represent a mechanism by which PMNs release thrombogenic signals during atherosclerosis and thrombosis may offer novel therapeutic targets (Table 1). Thrombolysis has become a key weapon in the arsenal against pathologic thrombosis; however, not all thrombotic events are susceptible to thrombolysis. Indeed, the addition of DNA and histones to a fibrin matrix has been shown to generate artificial thrombus more resistant to tissue plasminogen activator, and which can be partially remedied by DNase (85). Preliminary data from murine models of DVT demonstrate inhibition of thrombus formation by DNase treatment prior to model establishment $(66,67)$. Although DNase treatment, which likely enhances thrombolysis, appears to harbor relevant therapeutic potential, its utility and applicability to prevention of NET formation or digestion of established NETs to reduce atherosclerotic lesion growth is debatable and will remain controversial (86). Moreover, knockout of neutrophil oxidase 2, a NET component, can result in accelerating disease in a murine model of lupus; therefore, caution is required in the selection of NET-associated molecular targets. Another potential target is NET-related platelet recruitment to the endothelium (37). Specifically, blockade of 
TABLE 1 | Potential targets for translation in the prevention of NET-mediated atherosclerosis and thrombosis.

\begin{tabular}{|c|c|c|c|c|}
\hline \multirow[t]{2}{*}{ Diseases } & \multirow[t]{2}{*}{ Target } & \multirow[t]{2}{*}{ Function } & \multicolumn{2}{|r|}{ Clinical implications } \\
\hline & & & Clinical therapies & Potential treatment \\
\hline \multirow[t]{6}{*}{ Atherosclerosis } & cfDNA & Stimulation of plasmacytoid dendritic cells & & Deoxyribonuclease (86) \\
\hline & MPO & Induction of ROS & & Ocimum tenuiflorum (89) \\
\hline & Cathepsin G & Attraction of monocyte & & $\begin{array}{l}\text { Ac-Phe-Val-Thr-(4-guanidine)-Phg(P)- } \\
\text { (OPh4-SMe)2 (90) }\end{array}$ \\
\hline & Cathelicidins & Attraction of monocyte & & \\
\hline & IL17 & Amplification of platelet aggregation & & \\
\hline & $\mathrm{IL}-1 \beta$ & $\begin{array}{l}\text { Amplification of inflammatory reaction; } \\
\text { stimulation to Th17 cells }\end{array}$ & Rimonabant (91) & \\
\hline \multirow[t]{10}{*}{ Venous thromboembolism } & Histones & Endothelial injury & & Activated protein C (62) \\
\hline & $\mathrm{NE}$ & Degradation of TFPI and fibrin & & Leu89 with alanine (69) \\
\hline & Cathepsin G & Degradation of fibrin and enhancement of fibrinolysis & & Leu89 with alanine (69) \\
\hline & P-selectin & Adherence to platelet & & $\begin{array}{l}\text { Anti-P-selectin aptamer; anti-P-selectin } \\
\text { glycoprotein ligand-1 inhibitory antibody (58) }\end{array}$ \\
\hline & VWF & Adherence to platelet & & $\begin{array}{l}\text { Anti-P-selectin glycoprotein ligand-1 } \\
\text { inhibitory antibody (92) }\end{array}$ \\
\hline & TF & Activation of coagulation cascade & & TFPI (93) \\
\hline & AT & Anticoagulation & & \\
\hline & APC & anticoagulation & & \\
\hline & Thrombin & Promotion of coagulation & & PAR-1 antagonists (94) \\
\hline & Fibrin & Promotion of coagulation & Urokinase; rtPA & \\
\hline
\end{tabular}

Antimicrobial proteins (1).

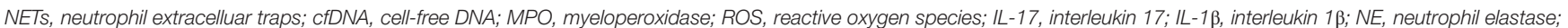
TFPI, tissue factor pathway inhibitor; VWF, von-Willebrand factor; TF, tissue factor; AT, antithrombin; PAR, proteinase-activated receptor; APC, activated protein C; rtPA, recombinant tissue plasminogen activator.

platelet alpha-granule or endothelial Weibel-Palade body release would decrease P-selectin- and vWF-mediated platelet and PMN recruitment to the endothelium, thereby decreasing NETosis (87). Similarly, vWF degradation enzyme could be administered to prevent PMN recruitment with subsequent NETosis (88). Although these countermeasures may result in mild immunodeficiency, they could also abrogate pathologic immune-mediated thrombosis without sacrificing immune competence when administered in a controlled manner. It is noteworthy that NETs are not major role players in these diseases but may definitely exacerbate the condition and therapies may have to be combinatorial because NET formation is only one of the factors.

\section{CONCLUSION}

Neutrophil extracellular trap-structure is an important novel discovery that has potential to influence our understanding of cardiovascular disease. Functionally, NETs can induce activation of ECs, antigen-presenting cells, and platelets, and cause endothelial dysfunction, resulting in a proinflammatory immune response. As evidenced by the results of the studies discussed above, NETs can clearly contribute to the initiation and progression of atherosclerotic and thrombotic lesions. Moreover, there is evidence for an emerging role of PMNs, focused on NETosis and

\section{REFERENCES}

1. Fuchs TA, Abed U, Goosmann C, Hurwitz R, Schulze I, Wahn V, et al. Novel cell death program leads to neutrophil extracellular traps. JCell Biol (2007) 176:231-41. doi:10.1083/jcb.200606027 oxidative stress burden, in orchestrating common mechanisms involved in various forms of cardiovascular disease. Extensive future research will be required to determine the effects of NETs in endothelial dysfunction-induced cardiovascular disease; hence, the time is not yet ideal to implement therapeutic options targeting neutrophils in the context of atherosclerosis and thrombosis.

\section{AUTHOR CONTRIBUTIONS}

HQ contributed to the conception of the study, consulting literatures, and manuscript preparation; SY make the figure and modify the manuscript; LZ helped perform the analysis with constructive discussions.

\section{ACKNOWLEDGMENTS}

All authors critically revised the review for intellectual content and approved the final version.

\section{FUNDING}

This work was supported by the National Natural Science Foundation of China grants (\#81670442 to LZ).

2. Brinkmann V, Reichard U, Goosmann C, Fauler B, Uhlemann Y Weiss DS, et al. Neutrophil extracellular traps kill bacteria. Science (2004) 303:1532-5. doi:10.1126/science. 1092385

3. Sorensen OE, Borregaard N. Neutrophil extracellular traps - the dark side of neutrophils. J Clin Invest (2016) 126:1612-20. doi:10.1172/JCI84538 
4. Lowe GD. Common risk factors for both arterial and venous thrombosis. Br J Haematol (2008) 140:488-95. doi:10.1111/j.1365-2141.2007.06973.x

5. Jorch SK, Kubes P. An emerging role for neutrophil extracellular traps in noninfectious disease. Nat Med (2017) 23:279-87. doi:10.1038/nm.4294

6. Xu J, Zhang X, Pelayo R, Monestier M, Ammollo CT, Semeraro F, et al. Extracellular histones are major mediators of death in sepsis. Nat Med (2009) 15:1318-21. doi:10.1038/nm.2053

7. Yipp BG, Kubes P. NETosis: how vital is it? Blood (2013) 122:2784-94. doi:10.1182/blood-2013-04-457671

8. Doring Y, Soehnlein O, Weber C. Neutrophil extracellular traps in atherosclerosis and atherothrombosis. Circ Res (2017) 120:736-43. doi:10.1161/ CIRCRESAHA.116.309692

9. de Buhr N, von Kockritz-Blickwede M. How neutrophil extracellular traps become visible. JImmunol Res (2016) 2016:4604713. doi:10.1155/2016/ 4604713

10. Zhao W, Fogg DK, Kaplan MJ. A novel image-based quantitative method for the characterization of NETosis. J Immunol Methods (2015) 423:104-10. doi:10.1016/j.jim.2015.04.027

11. Delgado-Rizo V, Martinez-Guzman MA, Iniguez-Gutierrez L, Garcia-Orozco A, Alvarado-Navarro A, Fafutis-Morris M. Neutrophil extracellular traps and its implications in inflammation: an overview. Front Immunol (2017) 8:81. doi:10.3389/fimmu.2017.00081

12. Pilsczek FH, Salina D, Poon KK, Fahey C, Yipp BG, Sibley CD, et al. A novel mechanism of rapid nuclear neutrophil extracellular trap formation in response to Staphylococcus aureus. J Immunol (2010) 185:7413-25. doi:10.4049/jimmunol.1000675

13. Karlsson A, Dahlgren C. Assembly and activation of the neutrophil NADPH oxidase in granule membranes. Antioxid Redox Signal (2002) 4:49-60. doi:10.1089/152308602753625852

14. Papayannopoulos V, Metzler KD, Hakkim A, Zychlinsky A. Neutrophil elastase and myeloperoxidase regulate the formation of neutrophil extracellular traps. J Cell Biol (2010) 191:677-91. doi:10.1083/jcb.201006052

15. Yousefi S, Mihalache C, Kozlowski E, Schmid I, Simon HU. Viable neutrophils release mitochondrial DNA to form neutrophil extracellular traps. Cell Death Differ (2009) 16:1438-44. doi:10.1038/cdd.2009.96

16. Papayannopoulos V, Zychlinsky A. NETs: a new strategy for using old weapons. Trends Immunol (2009) 30:513-21. doi:10.1016/j.it.2009.07.011

17. Urban CF, Ermert D, Schmid M, Abu-Abed U, Goosmann C, Nacken W, et al. Neutrophil extracellular traps contain calprotectin, a cytosolic protein complex involved in host defense against Candida albicans. PLoS Pathog (2009) 5:e1000639. doi:10.1371/journal.ppat.1000639

18. Wang Y, Li M, Stadler S, Correll S, Li P, Wang D, et al. Histone hypercitrullination mediates chromatin decondensation and neutrophil extracellular trap formation. J Cell Biol (2009) 184:205-13. doi:10.1083/jcb.200806072

19. Wang S, Wang Y. Peptidylarginine deiminases in citrullination, gene regulation, health and pathogenesis. Biochim Biophys Acta (2013) 1829:1126-35. doi:10.1016/j.bbagrm.2013.07.003

20. Li P, Li M, Lindberg MR, Kennett MJ, Xiong N, Wang Y. PAD4 is essential for antibacterial innate immunity mediated by neutrophil extracellular traps. J Exp Med (2010) 207:1853-62. doi:10.1084/jem.20100239

21. Zabieglo K, Majewski P, Majchrzak-Gorecka M, Wlodarczyk A, Grygier B, Zegar A, et al. The inhibitory effect of secretory leukocyte protease inhibitor (SLPI) on formation of neutrophil extracellular traps. JLeukoc Biol (2015) 98:99-106. doi:10.1189/jlb.4AB1114-543R

22. Rossaint J, Herter JM, Van Aken H, Napirei M, Doring Y, Weber C, et al. Synchronized integrin engagement and chemokine activation is crucial in neutrophil extracellular trap-mediated sterile inflammation. Blood (2014) 123:2573-84. doi:10.1182/blood-2013-07-516484

23. Hansson GK, Hermansson A. The immune system in atherosclerosis. Nat Immunol (2011) 12:204-12. doi:10.1038/ni.2001

24. Drechsler M, Megens RT, van Zandvoort M, Weber C, Soehnlein O. Hyperlipidemia-triggered neutrophilia promotes early atherosclerosis. Circulation(2010)122:1837-45.doi:10.1161/CIRCULATIONAHA.110.961714

25. Galligan C, Yoshimura T. Phenotypic and functional changes of cytokine-activated neutrophils. Chem Immunol Allergy (2003) 83:24-44. doi:10.1159/000071555

26. Stark MA, Huo Y, Burcin TL, Morris MA, Olson TS, Ley K. Phagocytosis of apoptotic neutrophils regulates granulopoiesis via IL-23 and IL-17. Immunity (2005) 22:285-94. doi:10.1016/j.immuni.2005.01.011
27. Christopher MJ, Link DC. Regulation of neutrophil homeostasis. Curr Opin Hematol (2007) 14:3-8. doi:10.1097/00062752-200701000-00003

28. Eash KJ, Greenbaum AM, Gopalan PK, Link DC. CXCR2 and CXCR4 antagonistically regulate neutrophil trafficking from murine bone marrow. J Clin Invest (2010) 120:2423-31. doi:10.1172/jci41649

29. Kougias P, Chai H, Lin PH, Yao Q, Lumsden AB, Chen C. Defensins and cathelicidins: neutrophil peptides with roles in inflammation, hyperlipidemia and atherosclerosis. JCell Mol Med (2005) 9:3-10. doi:10.1111/ j.1582-4934.2005.tb00332.x

30. Wang J, Sjoberg S, Tang TT, Oorni K, Wu W, Liu C, et al. Cathepsin G activity lowers plasma LDL and reduces atherosclerosis. Biochim Biophys Acta (2014) 1842:2174-83. doi:10.1016/j.bbadis.2014.07.026

31. Soehnlein O, Zernecke A, Eriksson EE, Rothfuchs AG, Pham CT, Herwald $\mathrm{H}$, et al. Neutrophil secretion products pave the way for inflammatory monocytes. Blood (2008) 112:1461-71. doi:10.1182/blood-2008-02-139634

32. Doring Y, Drechsler M, Wantha S, Kemmerich K, Lievens D, Vijayan S, et al. Lack of neutrophil-derived CRAMP reduces atherosclerosis in mice. Circ Res (2012) 110:1052-6. doi:10.1161/circresaha.112.265868

33. Wantha S, Alard JE, Megens RT, van der Does AM, Doring Y, Drechsler M, et al. Neutrophil-derived cathelicidin promotes adhesion of classical monocytes. Circ Res (2013) 112:792-801. doi:10.1161/circresaha.112.300666

34. Carbone F, Mach F, Montecucco F. Update on the role of neutrophils in atherosclerotic plaque vulnerability. Curr Drug Targets (2015) 16:321-33. doi:10.2174/1389450115666141110093013

35. Chistiakov DA, Bobryshev YV, Orekhov AN. Neutrophil's weapons in atherosclerosis. Exp Mol Pathol (2015) 99:663-71. doi:10.1016/j.yexmp.2015. 11.011

36. Warnatsch A, Ioannou M, Wang Q, Papayannopoulos V. Inflammation. Neutrophil extracellular traps license macrophages for cytokine production in atherosclerosis. Science (2015) 349:316-20. doi:10.1126/science. aaa8064

37. Knight JS, Luo W, O'Dell AA, Yalavarthi S, Zhao W, Subramanian V, et al. Peptidylarginine deiminase inhibition reduces vascular damage and modulates innate immune responses in murine models of atherosclerosis. Circ Res (2014) 114:947-56. doi:10.1161/CIRCRESAHA.114.303312

38. Doring $\mathrm{Y}$, Manthey HD, Drechsler M, Lievens D, Megens RT, Soehnlein $\mathrm{O}$, et al. Auto-antigenic protein-DNA complexes stimulate plasmacytoid dendritic cells to promote atherosclerosis. Circulation (2012) 125:1673-83. doi:10.1161/CIRCULATIONAHA.111.046755

39. Macritchie N, Grassia G, Sabir SR, Maddaluno M, Welsh P, Sattar N, et al. Plasmacytoid dendritic cells play a key role in promoting atherosclerosis in apolipoprotein E-deficient mice. Arterioscler Thromb Vasc Biol (2012) 32:2569-79. doi:10.1161/ATVBAHA.112.251314

40. Libby P, Ridker PM, Hansson GK. Progress and challenges in translating the biology of atherosclerosis. Nature (2011) 473:317-25. doi:10.1038/ nature 10146

41. Horne BD, Anderson JL, John JM, Weaver A, Bair TL, Jensen KR, et al. Which white blood cell subtypes predict increased cardiovascular risk? J Am Coll Cardiol (2005) 45:1638-43. doi:10.1016/j.jacc.2005.02.054

42. Distelmaier K, Adlbrecht C, Jakowitsch J, Winkler S, Dunkler D, Gerner C, et al. Local complement activation triggers neutrophil recruitment to the site of thrombus formation in acute myocardial infarction. Thromb Haemost (2009) 102:564-72. doi:10.1160/th09-02-0103

43. Ramaiola I, Padro T, Pena E, Juan-Babot O, Cubedo J, Martin-Yuste V, et al. Changes in thrombus composition and profilin-1 release in acute myocardial infarction. Eur Heart J (2015) 36:965-75. doi:10.1093/eurheartj/ ehu356

44. Yunoki K, Naruko T, Sugioka K, Inaba M, Iwasa Y, Komatsu R, et al. Erythrocyte-rich thrombus aspirated from patients with ST-elevation myocardial infarction: association with oxidative stress and its impact on myocardial reperfusion. Eur Heart J (2012) 33:1480-90. doi:10.1093/eurheartj/ ehr486

45. Silvain J, Collet JP, Nagaswami C, Beygui F, Edmondson KE, BellemainAppaix A, et al. Composition of coronary thrombus in acute myocardial infarction. J Am Coll Cardiol (2011) 57:1359-67. doi:10.1016/j.jacc.2010.09.077

46. Stakos DA, Kambas K, Konstantinidis T, Mitroulis I, Apostolidou E, Arelaki S, et al. Expression of functional tissue factor by neutrophil extracellular traps in culprit artery of acute myocardial infarction. Eur Heart J (2015) 36:1405-14. doi:10.1093/eurheartj/ehv007 
47. Borissoff JI, Joosen IA, Versteylen MO, Brill A, Fuchs TA, Savchenko AS, et al. Elevated levels of circulating DNA and chromatin are independently associated with severe coronary atherosclerosis and a prothrombotic state. Arterioscler Thromb Vasc Biol (2013) 33:2032-40. doi:10.1161/ATVBAHA. 113.301627

48. de Boer OJ, Li X, Teeling P, Mackaay C, Ploegmakers HJ, van der Loos CM, et al. Neutrophils, neutrophil extracellular traps and interleukin-17 associate with the organisation of thrombi in acute myocardial infarction. Thromb Haemost (2013) 109:290-7. doi:10.1160/TH12-06-0425

49. Mangold A, Alias S, Scherz T, Hofbauer T, Jakowitsch J, Panzenbock A, et al. Coronary neutrophil extracellular trap burden and deoxyribonuclease activity in ST-elevation acute coronary syndrome are predictors of STsegment resolution and infarct size. Circ Res (2015) 116:1182-92. doi:10.1161/ CIRCRESAHA.116.304944

50. Maugeri N, Campana L, Gavina M, Covino C, De Metrio M, Panciroli C, et al. Activated platelets present high mobility group box 1 to neutrophils, inducing autophagy and promoting the extrusion of neutrophil extracellular traps. J Thromb Haemost (2014) 12:2074-88. doi:10.1111/jth.12710

51. Stark K, Philippi V, Stockhausen S, Busse J, Antonelli A, Miller M, et al. Disulfide HMGB1 derived from platelets coordinates venous thrombosis in mice. Blood (2016) 128:2435-49. doi:10.1182/blood-2016-04-710632

52. Riegger J, Byrne RA, Joner M, Chandraratne S, Gershlick AH, Ten Berg JM, et al. Histopathological evaluation of thrombus in patients presenting with stent thrombosis. A multicenter European study: a report of the prevention of late stent thrombosis by an interdisciplinary global European effort consortium. Eur Heart J (2016) 37:1538-49. doi:10.1093/eurheartj/ ehv419

53. Darbousset R, Thomas GM, Mezouar S, Frere C, Bonier R, Mackman N, et al. Tissue factor-positive neutrophils bind to injured endothelial wall and initiate thrombus formation. Blood (2012) 120:2133-43. doi:10.1182/ blood-2012-06-437772

54. Savchenko AS, Borissoff JI, Martinod K, De Meyer SF, Gallant M, Erpenbeck L, et al. VWF-mediated leukocyte recruitment with chromatin decondensation by PAD4 increases myocardial ischemia/reperfusion injury in mice. Blood (2014) 123:141-8. doi:10.1182/blood-2013-07-514992

55. Di Nisio M, van Es N, Buller HR. Deep vein thrombosis and pulmonary embolism. Lancet (2016) 388:3060-73. doi:10.1016/S0140-6736(16) 30514-1

56. Xu S, Li X, LaPenna KB, Yokota SD, Huke S, He P. New insights into shear stress-induced endothelial signaling and barrier function: cell-free fluid verses blood flow. Cardiovasc Res (2017) 113(5):508-18. doi:10.1093/cvr/cvx021

57. Michels A, Albanez S, Mewburn J, Nesbitt K, Gould TJ, Liaw PC, et al. Histones link inflammation and thrombosis through the induction of Weibel-Palade body exocytosis. J Thromb Haemost (2016) 14:2274-86. doi:10.1111/jth.13493

58. Etulain J, Martinod K, Wong SL, Cifuni SM, Schattner M, Wagner DD. P-selectin promotes neutrophil extracellular trap formation in mice. Blood (2015) 126:242-6. doi:10.1182/blood-2015-01-624023

59. Savchenko AS, Martinod K, Seidman MA, Wong SL, Borissoff JI, Piazza G, et al. Neutrophil extracellular traps form predominantly during the organizing stage of human venous thromboembolism development. J Thromb Haemost (2014) 12:860-70. doi:10.1111/jth.12571

60. Clark SR, Ma AC, Tavener SA, McDonald B, Goodarzi Z, Kelly MM, et al. Platelet TLR4 activates neutrophil extracellular traps to ensnare bacteria in septic blood. Nat Med (2007) 13:463-9. doi:10.1038/nm1565

61. Gupta AK, Joshi MB, Philippova M, Erne P, Hasler P, Hahn S, et al. Activated endothelial cells induce neutrophil extracellular traps and are susceptible to NETosis-mediated cell death. FEBS Lett (2010) 584:3193-7. doi:10.1016/j. febslet.2010.06.006

62. Saffarzadeh M, Juenemann C, Queisser MA, Lochnit G, Barreto G, Galuska SP, et al. Neutrophil extracellular traps directly induce epithelial and endothelial cell death: a predominant role of histones. PLoS One (2012) 7:e32366. doi:10.1371/journal.pone.0032366

63. Semeraro F, Ammollo CT, Morrissey JH, Dale GL, Friese P, Esmon NL, et al. Extracellular histones promote thrombin generation through plateletdependent mechanisms: involvement of platelet TLR2 and TLR4. Blood (2011) 118:1952-61. doi:10.1182/blood-2011-03-343061

64. Gould TJ, Vu TT, Swystun LL, Dwivedi DJ, Mai SH, Weitz JI, et al. Neutrophil extracellular traps promote thrombin generation through platelet-dependent and platelet-independent mechanisms. Arterioscler Thromb Vasc Biol (2014) 34:1977-84. doi:10.1161/atvbaha.114.304114

65. Fuchs TA, Brill A, Duerschmied D, Schatzberg D, Monestier M, Myers DD Jr, et al. Extracellular DNA traps promote thrombosis. Proc Natl Acad Sci U S A (2010) 107:15880-5. doi:10.1073/pnas.1005743107

66. Brill A, Fuchs TA, Savchenko AS, Thomas GM, Martinod K, De Meyer SF, et al. Neutrophil extracellular traps promote deep vein thrombosis in mice. J Thromb Haemost (2012) 10:136-44. doi:10.1111/j.1538-7836.2011. 04544.x

67. von Bruhl ML, Stark K, Steinhart A, Chandraratne S, Konrad I, Lorenz M, et al. Monocytes, neutrophils, and platelets cooperate to initiate and propagate venous thrombosis in mice in vivo. JExp Med (2012) 209:819-35. doi:10.1084/jem.20112322

68. Ramacciotti E, Hawley AE, Farris DM, Ballard NE, Wrobleski SK, Myers DD Jr, et al. Leukocyte- and platelet-derived microparticles correlate with thrombus weight and tissue factor activity in an experimental mouse model of venous thrombosis. Thromb Haemost (2009) 101:748-54. doi:10.1160/TH08-09-0620

69. Massberg S, Grahl L, von Bruehl ML, Manukyan D, Pfeiler S, Goosmann C, et al. Reciprocal coupling of coagulation and innate immunity via neutrophil serine proteases. Nat Med (2010) 16:887-96. doi:10.1038/nm.2184

70. van Montfoort ML, Stephan F, Lauw MN, Hutten BA, Van Mierlo GJ, Solati S, et al. Circulating nucleosomes and neutrophil activation as risk factors for deep vein thrombosis. Arterioscler Thromb Vasc Biol (2013) 33:147-51. doi:10.1161/atvbaha.112.300498

71. Ward CM, Tetaz TJ, Andrews RK, Berndt MC. Binding of the von Willebrand factor Al domain to histone. Thromb Res (1997) 86:469-77. doi:10.1016/ S0049-3848(97)00096-0

72. Longstaff C, Hogwood J, Gray E, Komorowicz E, Varju I, Varga Z, et al. Neutralisation of the anti-coagulant effects of heparin by histones in blood plasma and purified systems. Thromb Haemost (2016) 115:591-9. doi:10.1160/th15-03-0214

73. Ammollo CT, Semeraro F, Xu J, Esmon NL, Esmon CT. Extracellular histones increase plasma thrombin generation by impairing thrombomodulindependent protein C activation. J Thromb Haemost (2011) 9:1795-803. doi:10.1111/j.1538-7836.2011.04422.x

74. Oklu R, Albadawi H, Watkins MT, Monestier M, Sillesen M, Wicky S. Detection of extracellular genomic DNA scaffold in human thrombus: implications for the use of deoxyribonuclease enzymes in thrombolysis. $J$ Vasc Interv Radiol (2012) 23:712-8. doi:10.1016/j.jvir.2012.01.072

75. Das R, Burke T, Plow EF. Histone H2B as a functionally important plasminogen receptor on macrophages. Blood (2007) 110:3763-72. doi:10.1182/ blood-2007-03-079392

76. Fuchs TA, Brill A, Wagner DD. Neutrophil extracellular trap (NET) impact on deep vein thrombosis. Arterioscler Thromb Vasc Biol (2012) 32:1777-83. doi:10.1161/ATVBAHA.111.242859

77. Diaz JA, Fuchs TA, Jackson TO, Kremer Hovinga JA, Lammle B, Henke PK, et al. Plasma DNA is elevated in patients with deep vein thrombosis. J Vasc Surg Venous Lymphat Disord (2013) 1:341-8. doi:10.1016/j. jvsv.2012.12.002

78. Engelmann B, Massberg S. Thrombosis as an intravascular effector of innate immunity. Nat Rev Immunol (2013) 13:34-45. doi:10.1038/nri3345

79. Ma AC, Kubes P. Platelets, neutrophils, and neutrophil extracellular traps (NETs) in sepsis. J Thromb Haemost (2008) 6:415-20. doi:10.1111/j.1538-7836. 2007.02865. $\mathrm{x}$

80. Yang S, Qi H, Kan K, Chen J, Xie H, Guo X, et al. Neutrophil extracellular traps promote hypercoagulability in patients with sepsis. Shock (2017) 47:132-9. doi:10.1097/shk.0000000000000741

81. Varju I, Longstaff C, Szabo L, Farkas AZ, Varga-Szabo VJ, Tanka-Salamon A, et al. DNA, histones and neutrophil extracellular traps exert anti-fibrinolytic effects in a plasma environment. Thromb Haemost (2015) 113:1289-98. doi:10.1160/TH14-08-0669

82. He Z, Si Y, Jiang T, Ma R, Zhang Y, Cao M, et al. Phosphotidylserine exposure and neutrophil extracellular traps enhance procoagulant activity in patients with inflammatory bowel disease. Thromb Haemost (2016) 115:738-51. doi:10.1160/TH15-09-0710

83. Huang YM, Wang H, Wang C, Chen M, Zhao MH. Promotion of hypercoagulability in antineutrophil cytoplasmic antibody-associated vasculitis by C5a-induced tissue factor-expressing microparticles and neutrophil 
extracellular traps. Arthritis Rheumatol (2015) 67:2780-90. doi:10.1002/ art.39239

84. Konig MF, Andrade F. A critical reappraisal of neutrophil extracellular traps and NETosis mimics based on differential requirements for protein citrullination. Front Immunol (2016) 7:461. doi:10.3389/fimmu.2016. 00461

85. Longstaff C, Varju I, Sotonyi P, Szabo L, Krumrey M, Hoell A, et al. Mechanical stability and fibrinolytic resistance of clots containing fibrin, DNA, and histones. J Biol Chem (2013) 288:6946-56. doi:10.1074/jbc.M112.404301

86. Vogel B, Shinagawa H, Hofmann U, Ertl G, Frantz S. Acute DNase1 treatment improves left ventricular remodeling after myocardial infarction by disruption of free chromatin. Basic Res Cardiol (2015) 110:15. doi:10.1007/ s00395-015-0472-y

87. Carestia A, Kaufman T, Rivadeneyra L, Landoni VI, Pozner RG, Negrotto S, et al. Mediators and molecular pathways involved in the regulation of neutrophil extracellular trap formation mediated by activated platelets. J Leukoc Biol (2016) 99:153-62. doi:10.1189/jlb.3A0415-161R

88. Schettert IT, Pereira AC, Lopes NH, Hueb WA, Krieger JE. Association between ADAMTS13 polymorphisms and risk of cardiovascular events in chronic coronary disease. Thromb Res (2010) 125:61-6. doi:10.1016/j. thromres.2009.03.008

89. Narasimhulu CA, Vardhan S. Therapeutic potential of Ocimum tenuiflorum as MPO inhibitor with implications for atherosclerosis prevention. J Med Food (2015) 18:507-15. doi:10.1089/jmf.2014.0125

90. Wang J, Sukhova GK, Liu J, Ozaki K, Lesner A, Libby P, et al. Cathepsin G deficiency reduces periaortic calcium chloride injury-induced abdominal aortic aneurysms in mice. J Vasc Surg (2015) 62:1615-24. doi:10.1016/j. jvs.2014.06.004

91. Dol-Gleizes F, Paumelle R, Visentin V, Mares AM, Desitter P, Hennuyer N, et al. Rimonabant, a selective cannabinoid CB1 receptor antagonist, inhibits atherosclerosis in LDL receptor-deficient mice. Arterioscler Thromb Vasc Biol (2009) 29:12-8. doi:10.1161/ATVBAHA.108.168757

92. Pendu R, Terraube V, Christophe OD, Gahmberg CG, de Groot PG, Lenting PJ, et al. P-selectin glycoprotein ligand 1 and beta2-integrins cooperate in the adhesion of leukocytes to von Willebrand factor. Blood (2006) 108:3746-52. doi:10.1182/blood-2006-03-010322

93. Osterud B. Tissue factor/TFPI and blood cells. Thromb Res (2012) 129:274-8. doi:10.1016/j.thromres.2011.11.049

94. Chackalamannil S, Xia Y. Thrombin receptor (PAR-1) antagonists as novel antithrombotic agents. Expert Opin Ther Pat (2006) 16:493-505. doi:10.1517/13543776.16.4.493

Conflict of Interest Statement: The authors declare that the research was conducted in the absence of any commercial or financial relationships that could be construed as a potential conflict of interest.

Copyright (c) 2017 Qi, Yang and Zhang. This is an open-access article distributed under the terms of the Creative Commons Attribution License (CC BY). The use, distribution or reproduction in other forums is permitted, provided the original author(s) or licensor are credited and that the original publication in this journal is cited, in accordance with accepted academic practice. No use, distribution or reproduction is permitted which does not comply with these terms. 